\title{
Moral Arguments in the Debate over Nanotechnologies: Are We Talking Past Each Other?
}

\author{
Johane Patenaude - Georges A. Legault • \\ Jean-Pierre Béland • Monelle Parent • \\ Patrick Boissy
}

Received: 5 July 2011 /Accepted: 10 October 2011 /Published online: 27 October 2011

(C) The Author(s) 2011. This article is published with open access at Springerlink.com

\begin{abstract}
How are we to understand the fact that the philosophical debate over nanotechnologies has been reduced to a clash of seemingly preprogrammed arguments and counterarguments that paralyzes all rational discussion of the ultimate ethical question of social acceptability in matters of nanotechnological development? With this issue as its starting point, the study reported on here, intended to further comprehension of the issues rather than provide a cause-andeffect explanation, seeks to achieve a rational grasp of what is being said through the appeals made to this or that principle in the range of arguments put forward in publications on the subject. We present the results of the study's analyses in two parts. In the first, we lay out the seven categories of argument that emerged from an analysis of the literature: the arguments based on nature, dignity, the good life, utility, equity, autonomy, and rights. In the second part, we present
\end{abstract}

J. Patenaude $\cdot$ G. A. Legault $\cdot$ M. Parent $\cdot$ P. Boissy

Université de Sherbrooke,

Sherbrooke, Canada

J.-P. Béland

Université du Québec à Chicoutimi,

Chicoutimi, Canada

J. Patenaude $(\bowtie)$

Department of Surgery, Faculty of Medicine,

Université de Sherbrooke,

3001, 12e Av. Nord,

Sherbrooke, Québec, Canada J1H 5N4

e-mail: Johane.Patenaude@USherbrooke.ca the background moral stances that support each category of argument. Identifying the different categories of argument and the moral stance that underlies each category will enable a better grasp of the reasons for the multiplicity of the arguments that figure in discussions of the acceptability of nanotechnologies and will ultimately contribute to overcoming the tendency towards talking past each other that all too often disfigures the exchange. Clarifying the implications of the moral arguments deployed in the debate over nanotechnologies may make it possible to reduce the confusion observable in these exchanges and contribute to a better grasp of the reasons for their current unproductiveness.

Keywords Acceptability - Debate on nanotechnology · Dialogue · Interdisciplinarity · Moral arguments · Nanoethics $\cdot$ Philosophy and nanotechnology $\cdot$ Social acceptability and nanotechnology

As has been pointed out by Jean-Pierre Dupuy ([4]: 238), philosophical debate over the ethical foundations of nanotechnology has become so routine that it would be easy to simply rhyme off the arguments regularly brought forward: 'The same arguments are always served up, and they are always answered with the same counter-arguments.' How are we to understand the fact that this philosophical debate has been reduced to a clash among seemingly preprogrammed arguments and counterarguments that are paralyzing 
all rational discussion of the ultimate ethical question of social acceptability in matters of nanotechnological development? The clash of multiple moral arguments in the public arena reflects a more basic question: that of whether dialogue on this issue is possible, or whether, on the contrary, we must all bid goodbye forever to the possible co-construction of meaning about the social acceptability of nanotechnologies.

Opting for dialogue requires that from the outset we seek to rationally understand what is being said through the appeals we encounter to this or that principle in the range of arguments advanced. This is the situation that faces philosophers when they participate in interdisciplinary research on the ethical, economical, environmental, legal, and social aspects of the development of nanotechnologies. How can philosophy contribute to this interdisciplinary dialogue if all it can offer is a clash among moral arguments? Our first concern in establishing a dialogue is to sort out the different stages of confusion in the ethical debate and to identify the sources of the incompatibility among the arguments in question. This analysis inquires into the types of rationality that support the various types of moral argument. it is thus very different than the Swiestra and Rib study [9], in which the starting point is a consideration of moral arguments as moral routines that clash with each other in social life.

From this context, the present article emerges as the product of an effort at clarification. The aim of the article is to provide a systematic account of the multiple moral arguments advanced in evaluating the social impact of developments in nanotechnology. To this end, we first conduct a brief overview of the threefold nature of a moral argument. We then inventory and analyze various categories of moral argument deployed by different authors in evaluating nanotechnologies. This then puts us in a position to identify the background moral stances that support the argument categories analyzed. Identifying the various categories of argument and the moral stance that underlies each will enable a better grasp of the reasons for the mutual irreducibility of the arguments that figure in discussions of the acceptability of nanotechnologies explains the tendency for participants in the debate to talk past each other.

\section{What is a Moral Argument?}

'Moral argument' refers to a meaning structure that supports one's evaluation of a situation or one's judgment on it. A moral argument appeals to reason, that is, to comprehensibility by others than oneself. The appeals to rationality made by a moral argument are of three kinds, with each kind being specific to a different component of the argument:

a) the appeal made by the meaning of the moral utterance;

b) the appeal made by the justification for the moral utterance's moral authority;

c) the appeal made by practical reason through the application of the moral utterance to a specific context (concrete case under discussion) .

The moral utterance makes an appeal to a moral principle or an ethical evaluation that guides judgment regarding a specific context. The distinction between norm-based ethics and value-based ethics has been established in applied ethics work in the context of corporate governance and in the work of certain francophone Canadian philosophers [6]. We apply it here to moral utterances. A moral utterance that appeals to a moral principle has the meaning that a situation is to be judged by the criterion of compliance with a moral principle. When a moral argument appeals to an ethical evaluation, it makes an appeal for judgement of a situation to be based not on compliance with to a norm but on an assessment of the situation as a means of actualizing a certain value or principle.

The justification for the moral utterance's moral authority consists of what is invoked as the moral utterance's foundations. Finally, the application of the moral utterance to a specific context consists of the process of practical reasoning by means of which the moral utterance is applied to the case under discussion, in order to arrive at a moral judgment or ethical evaluation of the case.

Debate over a given moral argument may focus on any one of these components. But a moral argument must comprise a clear utterance of a moral principle; a clear presentation of the foundations for that principle's moral authority; and a process of practical reasoning that makes it possible to pass from the principle invoked in the moral utterance to a concrete situation. That these three components must be 
present is entailed by the minimum philosophical requirement for moral argument, namely that it constitute a rational activity going beyond the mere invocation of a moral concept-for example, dignitythat is then tossed about as a key word in the discourse around the issue in question. Absent any one of the three components, an argument cannot be called rational. Instead, it takes on the quality of a conviction or an ideology, that is, a stance involving varying degrees of rationality that is accordingly difficult to subject to discussion.

With these components as a basis for analysis, we find that an impressive number of diverse moral arguments are scattered through the literature on the evaluation of nanotechnologies. Each instance of moral evaluation seeks to measure the consequences of nanotechnologies by deploying its own criteria. To better assess the current state of discussion on the matter, we undertook to identify the moral arguments deployed in the literature on nanotechnologies and determine the range of their diversity. The next section describes the method we used to do this.

\section{Methods}

We first conducted a review of the literature to identify the texts (reports, books, and articles) in which moral arguments are deployed to support or oppose the development of nanotechnologies. We identified some texts found in certain reports (including the NSF Report, 2009) dealing with the arguments and counterarguments around the ethical issues associated with nanotechnologies and 16 articles published in the journal NanoEthics; as well, we ran general key words through search engines in an effort to canvass the broadest possible range of arguments invoked in connection with this subject and confirm we had reached data saturation. Once we had reached saturation, we had a bank of 24 texts. Each was analyzed using an analytic framework designed to classify the arguments we had gathered. This classification was performed at several levels, including that of the various categories of argument deployed, so that we might extract the 'core meaning' of each and their respective underlying moral stances. Using a second level of analysis [12], we identified the main critiques demonstrating that the limitations of these opposed arguments risk dooming the discussion to an impasse. Finally, a third level of analysis in our classification process enabled us to better gauge whether philosophical dialogue is possible regarding the epistemological and moral impasses that form the background to conflicts among the previously identified categories of moral argument.

In the next section, we report on the results of our first level of classification, the one that, as explained, reveals the multiplicity of categories of moral argument deployed and the core meaning in each. These results rely on an analysis of the first of the three components of a moral argument, namely the moral utterance, as found in the texts reviewed. In the subsequent section, based on the two other components of a moral argument, namely the justification for the moral utterance's moral authority and the application of the moral utterance to a concrete case, we offer an account of the moral stances underlying the various categories of moral argument.

\section{The Categories of Argument}

Analyzing the moral utterance component of moral arguments yielded the finding that seven broad families or categories of argument can be identified: the arguments based on nature, dignity, the good life, utility, equity, autonomy, and rights.

Category 1: The argument based on nature and based on metaphysical human nature

This category of argument demands compliance with nature: nature represents a norm that we cannot violate without risk or that we must follow in order to remain in harmony with it.

Core meaning: Act in accordance with nature and make sure your actions maintain harmony with nature. For example: '[N]anotechnological developments will not only transgress physical barriers in unheard of ways, but also spiritual and moral barriers, by clashing with a predetermined order of things.' ([7]: 119).

Category 2: The argument based on human dignity

This is the Kantian argument of human dignity, according to which the human being must always be viewed as an end in herself or himself and never as a means to another thing.

Core meaning: Act in such a way that you treat humanity 'never merely as a means, but always at the same time as an end' ([5]: 33). It is this category of argument that is referred to in these passages: 
'Kantianism or, more generally, an ethics of duty (deontology) is ... to the most fundamental questions raised by the nanotechnological project...' ([4]: 238); and here: 'The second version [of the appeal to human dignity], that is, the invocation of the integrity, or of the dignity, of the human being, is more delicate to handle' ([7]: 120).

Category 3: The argument based on the good life

Here we are dealing with the Aristotelian argument based on the idea of the good life.

Core meaning: The ethical choice consists of determining the kind of life we wish to live together as human beings. For example: "[T]he "improvements" advanced by the transhumanists are distant from the ideal of the happy medium advanced by the ethics of virtues; rather, they assume the form of what Antiquity depicted with the disgraceful features of excess' ([7]:117).

Category 4: The argument based on utility

This is the argument according to which the best choice consists of the net maximization of positive consequences over negative consequences for human beings.

Core meaning: "Act in such a way that your choices maximize positive consequences over negative consequences for the largest number of people.' For example:

Utilitarianism, simply, defines ethical acceptability in terms of consequences, specifically, positive net outcomes of actions. If an action (or development or use of a technology) makes more people happy, or satisfies more of the people's preferences, then that action is ethically acceptable. ([2]:57)

Category 5: The argument based on equity

Under this category of argument, individuals and groups must be treated in the same way once their shared membership in a single reference category has been acknowledged.

Core meaning: 'Act in such a way that people who are members of the same reference category are treated in the same way.' For example: 'Does human enhancement raise issues of fairness, access, and equity? ...It is feared by some that nanotechnology will also sharpen and widen divisions both within societies and between nations: a nanodivide will be created' ([1]:21).

Category 6: The argument based on autonomy

This is the category of argument based on complete freedom in conducting one's life. The ethical choice is that which an individual makes as a self-determining subject.

Core meaning: Act according to your individual choices. For this we have two examples. The first is this statement by Cole (1998) as quoted by Burkhardt ([2]: 66): 'Autonomy means self-determination, and if our primary ethical responsibility is to respect selfdetermination then individual preferences or choices cannot be written off or ignored for the sake of the maximum good.' Burkhardt continues in his own voice, 'In fact, according to the rights/autonomy principle, any "social good" has to be defined as providing or allowing individuals the freedom to chose. This freedom includes the freedom to avoid [genetically modified] foods for whatever reasons the individual sees fit.' ([2]: 66)

Category 7: The argument based on rights

According to this category of argument, in a liberal democracy, self-determination must be considered a fundamental right and serves as the basis for legal responsibility.

Core meaning: 'Act according to your individual choices and within the limits of existing laws.' For example: 'Accordingly, there can be no trade-off, no "balancing," no calculating net gains. Even though an action may achieve utilitarian gains, or serve some greater social good, if individuals have certain rights against that action, it is wrong.' [2]

There is, then, a significantly wide range of moral utterances about nanotechnologies, which, when they are analyzed based on their core meanings, can be reduced to the seven categories of moral argument presented above. Furthermore, each of the seven categories of argument claims normative force (to forbid or to authorize) or puts forward a criterion for evaluation with which to judge acceptability (good/ bad) and each constitutes its own universe of meaning, one that cannot be reduced to the universe of meaning of any of the others.

The two other components of a moral argument, namely the justification for the moral utterance's moral authority and the application of the moral utterance to a concrete case, reveal with greater precision the irreducible nature of the moral stances underlying each of these seven categories of argument. It is not hard to clarify the first dimension of the mutual irreducibility of these arguments : it resides in the background epistemological positions to the moral arguments deployed. Thus the arguments based on 
nature, dignity, and the good life are all based on knowledge of nature, human nature, or the human condition and postulate that such knowledge is possible. Advancing a different approach to rationality than that of moral knowledge are the moral arguments based on utility and equity, which rest on an evaluation of a specific case. Finally, some arguments do not recognize a moral foundation other than individual or social choices. The argument based on autonomy, when it is not founded on the existence of a human nature, is integrated into the arguments based on rights. These arguments are based on social choices to be made without reference to a moral background and thus they shift from philosophy to politics.

Let us take a closer look at these various epistemological stances.

\section{Background Epistemological Stances to the Moral Arguments}

Stance 1: Nature and Metaphysical Human Nature

In moral arguments that deploy the principle of the knowledge of nature and human nature, the moral utterances with which nanotechnologies are evaluated consist of a prescription. The moral utterance specifies what we must or must not do, based on what we know of the laws that govern nature and our human nature. The whole of the rational justification that serves as the basis for the moral prescription's authority consists of our capacity to understand these laws inscribed in nature and our own human nature. It is, in fact, knowledge of these laws that enables us to understand our obligations. Under this type of moral justification, it is human membership in nature or in the human species that makes it possible, thanks to the transcendence of laws over individuals and to the feeling of belonging, to mobilize individuals to act in compliance with moral rules.

Application of this prescription to a concrete situation requires practical reasoning consisting of recognizing that such-and-such an action in such-andsuch a context represents an instance of deviation from what the moral prescription would stipulate. Thus practical reasoning would appear to consist essentially of identifying the type of action involved in a situation and comparing it with all the possible actions that could violate the moral prescription logically or formally.

Stance 2: Human Nature (a Priori Conditions for Moral Experience)

In moral arguments of the Kantian type, we find a moral prescription that expresses the condition for possibility of our moral actions. This prescription is very general and is aimed essentially at identifying the relationship we should have with other human beings. According to Robert Theis ([10]: paragraphs 20 and 23), it is this formulation of the categorical imperative that constitutes the center of gravity for the various ways the principle has been framed: 'Act in such a way that you treat humanity, whether in your own person or in the person of any other, never merely as a means to an end, but always at the same time as an end' ([5]: 30). This command, 'Act', concerns how we orient our ability to act. It is the universal nature of humanity as an end in itself, as found within oneself and others, that the prescription sets as transcendent. To the extent that the Kantian approach is designed to address the limitations of metaphysical knowledge, moral justification here is based on transcendental inquiry. Whereas we cannot have access to knowledge of things in themselves, to 'the real', we can have access to knowledge of what makes possible our experience of knowledge, or our moral experience. Transcendental inquiry, then, makes it possible to identify these conditions for possibility of our experience. The categorical imperative is the result of transcendental analysis of the will to act morally. For Kant, moral action is distinguished from acting according to one's desires, and the objective moral end of the human being is distinguished from the subjective end linked to the desire for happiness. Theis ([10]: paragraph 41) specifies: 'Ends can be subjective or objective. A subjective end concerns the individual and is a function of some object of the individual's faculty for desiring: it constitutes a motive. On the other hand, an objective end is universal and constitutes a determining principle of the will as will. As such, an objective end is a duty. Moral law constitutes just such an end.'

While the categorical imperative stipulates the ultimate nature of the human being as an end in herself or himself and the prohibition against treating the human being only as a means, the work of Kant 
provides us with few specifics about concrete means for evaluating choices such as those related to the development of nanotechnologies. It is possible that practical questions, such as that of lying or the possibility of disposing of one's own body as one wishes, will in fact find answers in the prescription to treat human beings as ends in themselves; but when it comes to other activities, in order to take the human being into account, we are obliged to establish a whole series of causal links among the various possible uses of nanotechnologies and the impacts of these uses on human beings.

\section{Stance 3: The Good Life}

The epistemological foundations for evaluating nanotechnologies by reference to the good life are very different from the foundations for reference to the good life presented by Aristotle, the first philosopher to articulate this concept as a basis for the moral evaluation of human action. While in Aristotle there existed a moral obligation for all human beings to act in accordance with their natures, this obligation imposed on human beings the need to make choices that would actualize their human potential. Thus the Aristotelian foundations relate more to arguments about human nature than to questions of the human condition. Post-Kantian moral philosophy must reflect human morality beyond the foundations given by nature and must also take into account the limitations of Kantian transcendental inquiry into human dignity. Arguments based on the concept of the good life seek to evaluate human choices according to their consequences for human life, from both an individual point of view and a social one. In Paul Ricoeur ([1990] [8]: 172), we find, as part of his celebrated definition of the purpose of ethics, the element of individual choice focused on happiness, but taking into account the other and institutions: 'aiming at the "good life" with and for others, in just institutions'. What distinguishes an approach of this kind from Aristotle's is the fact that the aim of ethics is not rooted in nature but is based rather on our human condition and the work of civilization. The moral justification for approaches based on the good life rests essentially on the moral experience of human beings through history. This ethos, which is based on failures and successes, leads us, by means of inquiry, to pinpoint a basis in collective experience, which serves to guide us in our future choices. While we are the product of history, we are also responsible for the history that is to come. Tradition serves as a guide, but, in the light of new experiences, it must reflect on itself and think itself in context. A sense of human experience through history - a strong sense of tradition-influences the choices that will have an impact on our future, because it constitutes the basis for what transcends our individual natures. Case-based reasoning makes it possible to apply the process of evaluation of the good life to a particular context. This evaluation of what is acceptable or not first requires knowledge of the consequences of choices for human life and then an evaluation of these consequences in light of the impact of the choices in question on our human condition. The more these changes distance us from our traditional ways and transform our individual and social living conditions, the more negative will be the evaluation. Our human condition, as it results from the collective history of humanity, thus makes it possible to establish certain guidelines for evaluating future paths according to their implications for the human condition.

\section{Stance 4: Value-Based Moral Evaluation}

The main form taken by the utilitarian moral arguments advanced to evaluate nanotechnologies is far different from the moral theory of John Stuart Mill or Jeremy Bentham. It comes down to an economic version of cost-benefit analysis. The locus of convergence of this analysis with utilitarian morality does not reside in the moral obligation to increase the general well-being of the largest number, but rather in performing an evaluation by means of a calculation of the cost of a given development. An accounting-style balance of costs and benefits is viewed as making possible the determination of the rational choice. The main criticisms made in response to this basis for argument raises the problem inherent in general formulations of a judgment value: 'What is a cost?', 'What is a benefit?' The fact is, the moral evaluation must judge the value to be ascribed to consequences in light of the evaluative category. Is such-and-such a consequence useful? Does such-and-such a consequence represent a cost? Is such-and-such a consequence a benefit? And how are we to keep these two evaluations in relationship with each other? ([9]: 12) To provide the practical reasoning which will serve as 
a basis for judging the consequences, it is necessary to specify the general value by assigning more precise criteria; and, from a philosophical perspective, it is necessary to justify what the choice of criteria is based on. Mill's moral philosophy rests on an analysis of human moral experience, just as does Kant's, although not with a view to determining a transcendental structure, but essentially with a practical goal of determining what human beings seek as well-being by virtue of being human. In contrast to Mill, who sought to identify that which is proper to human beings in order to define utility, economics-based thinking proposes that we should consider every value in light of the quest to maximize personal happiness. With utilitarian evaluation, it is in the sphere of application that difficulties emerge. The first difficulty often relates to the level of generality of the criterion to apply. The second is rooted in the difficulty of identifying consequences. Not all consequences are evident. The debate over human toxicity already provides an example of this difficulty in the sphere of science. What is to be done when we consider social consequences? How are we to determine these consequences? In other words, how will the utilitarian analysis be able to take account of uncertainty in producing its balance sheet?

Another category of argument, that of equity, also rests on moral evaluation. Like utilitarian arguments, arguments based on equity claim that we cannot accept something socially if it does not satisfy equitybased criteria. It may seem surprising to place utilitarianism and equity on the same footing, because the work done by Rawls appears to many to be a fundamental critique of utilitarianism. The resemblance between the two resides in the way the moral utterances are structured. In both cases, it's a question of evaluating consequences. The difference resides in the specific nature of the evaluation. Whereas in utilitarianism evaluation is done by people involved in social life in order to determine what is most useful to the greatest number, in Rawls's analysis, whether it's a question of individual or collective decisions, rational rules are to be established as the basis for social choices within a democratic society. Utilitarianism is reproached with producing decisions that in reality may sacrifice some individuals or groups for the benefit of the majority: Rawls seeks to establish a theory of collective decision making that allows for avoiding such a sacrifice of some in favor of others.
The argument based on equity has Kantian overtones, but it is built on a collective and not an individual basis.

The justification for Rawls's moral theory rests on the bases found within the English-speaking tradition, namely those of reflection on moral experience. Rawls calls this process 'reflective equilibrium': it consists of reflecting on our practices and our conflicts in moral judgment on the basis of our sense of justice, in order to arrive at a balance among various beliefs and ensure consistent action is taken. In applying this process to democracy, Rawls sees that one way of ensuring such a sense of justice is to place the humans who are to decide on a constitution under a veil of ignorance. Thus no single person knows what position she or he will occupy in society. It is by eliminating personal interests and personal attitudes and beliefs that the rule of equity can be formulated.

As with utilitarianism, the application of evaluation on the basis of equity requires a case-by-case approach. '[S] uch an approach should deal with ethical issues in their real-world context rather than taking them as abstract ethical issues that can be solved by applying existing ethical concepts and theories' ([11]: 34). However, we must never forget that this principle can only be applied to situations involving social distribution. It is no surprise that it tends to be questions of equitable distribution of the windfalls of nanotechnology that bring this argument into play.

\section{Stance 5: Moral Subjectivism}

The first four bases for moral argument assume the existence of a dimension that transcends individuals and subsumes them, whether by means of natural law, or by the fact of membership in the human race, or in virtue of accumulated human experience through history and within institutions. Thanks to this transcendent element, it is possible to identify obligations that we have in both our individual and our collective lives. Moral subjectivism declares that every morality is individual and every individual choice must be respected because the only moral authority is the subject. It recognizes no transcendental dimension as serving as a guide to moral action.

Moral subjectivism rests essentially on a psychosocial approach that postulates that everything related 
to action, decision making, and the motivation to act is based on emotions and preferences. Thus all moral language, even the commandment 'Thou shalt not kill', is nothing more than the expression of a negative emotion (in the instance cited here, negative emotion in the face of murder) and the expression of a preference for a way of living in society. Moral judgments or declarations are no more than an expression of approval or disapproval towards certain behaviors. In this perspective, there thus exists no rational or moral dimension; this is why all the previous categories of argument are irrelevant to the evaluation of technological development.

What is to be done in the face of the multiplicity of individual choices, given that there is no rational means of discussing preferences? The answer is that social control is made possible by a theory of rights. And this indeed is the basis in law for legal responsibility. Every individual is liable for damages caused to another. The Québec [3] does allow for exceptions, however:

1473. The manufacturer, distributor or supplier of a movable property is not liable to reparation for injury caused by a safety defect in the property if he proves that the victim knew or could have known of the defect, or could have foreseen the injury.

Nor is he liable to reparation if he proves that, according to the state of knowledge at the time that he manufactured, distributed or supplied the property, the existence of the defect could not have been known, and that he was not neglectful of his duty to provide information when he became aware of the defect.

Under this approach, limitations on a person's rights may be contemplated solely when there exists an already known risk, and this only according to the knowledge that was available at the moment of manufacture. The absolute autonomy of the subject is bounded only when there are consequences harmful to others. In this perspective, consequences to the environment only take on meaning according to the impact of the environment on individuals.

\section{Conclusion}

Analysis of the moral arguments has made it possible to clarify their argumentative structure. This allows for avoiding misunderstanding; for example, misunderstanding about the various semantic units of the principle of human dignity when used in a Kantian sense as opposed to a libertarian sense. Moreover, this analysis makes it possible to show the following: understanding the way moral arguments are irreducible to each other requires clear moral utterances stating the principles invoked, specifics about the basis for justification of those moral utterances' moral authority, and practical reasoning that enables the passage from the moral utterance to a concrete situation. As well, once the moral stances in the background of the various categories of moral argument were identified, we were able to demonstrate what the multiplicity of the arguments ultimately derives from.

Analysis of the moral arguments also showed the difference between, on one hand, those moral utterances that clearly specify obligations to act or prohibitions against action, such as the arguments based on nature and human nature, dignity, and the good life, and, on the other hand, those that advance principles such as utility and equity as bases for evaluation. The analysis also showed that the argument based on autonomy only has moral implications when associated with the argument based on rights. These moral utterances were systematically analyzed from the point of view of moral epistemology and that of practical reason in order to identify what is particular to them. It was this that brought to light five moral stances underlying the seven categories of argument.

These distinctions and systematic analyses are intended to contribute to a reduction in the confusion that is too often present in the debate over nanotechnologies. They reveal the mutually irreducible nature of the five moral stances identified. The first form of irreductibility resides in the possibility of knowing moral obligations or the human condition as a moral fact. Three different epistemological positions are found here: the rationality of moral obligation, the rationality of a value-based evaluation; and the absence of rationality. The second form of irreducibility resides in the conceptions of practical reasoning that correspond to the epistemological positions.

It remains to understand why these irreducible stances cannot engage in dialogue with each other. In other words, are we condemned to talk past each other? Before analysing the different ways of dealing 
with the mutual irreducibility of moral arguments such as those advanced by philosophers like Habermas and Rawls, we must deepen our analysis of the impasses in the dialogue on moral arguments [12].

Acknowledgments This study is currently being funded by a grant from the Canadian Institutes for Health Research (CIHR) entitled: "Development of an interdisiciplinary framework for the analysis of the impact of nanotechnologies on health and of their social acceptability." (no.191080).

Open Access This article is distributed under the terms of the Creative Commons Attribution Noncommercial License which permits any noncommercial use, distribution, and reproduction in any medium, provided the original author(s) and source are credited.

\section{References}

1. Allhoff F, Lin P, Moore J, Weckert J (2009) Ethics of human enhancement: 25 questions and answers. (US National Science Foundation Report)

2. Burkhardt J (2008) The ethics of agri-food biotechnology: how can an agricultural technology be so important? In: David K, Thompson PB (eds) What can nanotechnology learn from biotechnology? Elsevier, USA, pp 5579

3. Québec (2011) Civil code of Québec. Québec, QC: Éditeur officiel du Québec. Retrieved June 30, 2011, from http://
www2.publicationsduquebec.gouv.qc.ca/dynamicSearch/ telecharge.php?type $=2 \&$ file $=/ \mathrm{CCQ} / \mathrm{CCQ} \cdot \mathrm{html}$

4. Dupuy JP (2007) Some pitfalls in the philosophical foundation of nanoethics. J Med Philos 32:237-261. doi:10.1080/03605310701396992

5. Kant I [1785] (1993). Grounding for the metaphysics of morals, translated by James W. Ellington, 3rd ed. (Indianapolis: Hackett)

6. Legault G-A (2007) Autorégulation et hétérorégulation: un concept interdisciplinaire. In L'autorégulation en éthique. Ethica 16(2):27-50

7. Nurock V (2008) Avons-nous vraiment besoin de « nano-éthique »? In: Bensaude-Vincent $\mathrm{B}$, Larrère R, Nurock V (eds) Bionano-éthique, perspectives critiques sur les bionanotechnologies. Éditions Vuibert, Paris, pp 113-126

8. Ricoeur P (1992) Oneself as another, translated by Kathleen Blamey (Soi-même comme un autre (Paris: Seuil, 1990)). University of Chicago Press, Chicago

9. Swierstra T, Rip A (2007) Nano-ethics as NEST-ethics: patterns of moral argumentation about new and emerging science and technology. NanoEthics 1:3-20

10. Theis R (2005) L'impératif catégorique, des énoncés à l'énonciation. Le portique, 15. Retrieved November 22, 2010, from http://leportique.revues.org/index 597.html

11. Van de Poel I (2008) How should we do nanoehics? a network approach for discerning ethical issues in nanotechnology. NanoEthics 2:25-38

12. Béland JP, Patenaude J, Legault GA, Boissy P, Parent M (2011) The Social and Ethical Acceptability of NBICs for Purposes of Human Enhancement: Why Does the Debate Remain Mired in Impasse? NanoEthics (In Press) 